\title{
Effects of Heat Acclimation and Acclimatisation on Maximal Aerobic Capacity Compared to Exercise Alone in Both Thermoneutral and Hot Environments: A Meta-Analysis and Meta-Regression
}

\author{
Mark Waldron $^{1,2,3}$ (D) $\cdot$ Rebecca Fowler $^{4} \cdot$ Shane Heffernan $^{1} \cdot$ Jamie Tallent $^{4} \cdot$ Liam Kilduff $^{1,2} \cdot$ Owen Jeffries $^{5}$
}

Accepted: 6 March 2021 / Published online: 3 April 2021

(c) The Author(s) 2021

\begin{abstract}
Background Heat acclimation and acclimatisation (HA) is typically used to enhance tolerance to the heat, thereby improving performance. HA might also confer a positive adaptation to maximal oxygen consumption $\left(V \mathrm{O}_{2 \max }\right)$, although this has been historically debated and requires clarification via meta-analysis.

Objectives (1) To meta-analyse all studies (with and without control groups) that have investigated the effect of HA on $V \mathrm{O}_{2 \max }$ adaptation in thermoneutral or hot environments; (2) Conduct meta-regressions to establish the moderating effect of selected variables on $\mathrm{VO}_{2 \text { max }}$ adaptation following $\mathrm{HA}$.

Methods A search was performed using various databases in May 2020. The studies were screened using search criteria for eligibility. Twenty-eight peer-reviewed articles were identified for inclusion across four separate meta-analyses: (1) Thermoneutral $V \mathrm{O}_{2 \text { max }}$ within-participants (pre-to-post $\mathrm{HA}$ ); (2) $\mathrm{Hot} V \mathrm{O}_{2 \max }$ within-participants (pre-to-post HA); (3) Thermoneutral $V \mathrm{O}_{2 \max }$ measurement; HA vs. control groups; (4) Hot $V \mathrm{O}_{2 \max }$ measurement, HA vs. control groups. Meta-regressions were performed for each meta-analysis based on: isothermal vs. iso-intensity programmes, days of heat exposure, HA ambient temperature $\left({ }^{\circ} \mathrm{C}\right)$, heat index, HA session duration (min), ambient thermal load (HA session $\mathrm{x}$ ambient temperature), mean mechanical intensity (W) and the post-HA testing period (days).

Results The meta-analysis of pre-post differences in thermoneutral $V \mathrm{O}_{2 \text { max }}$ demonstrated small-to-moderate improvements in $V \mathrm{O}_{2 \max }$ (Hedges' $g=0.42,95 \%$ CI $0.24-0.59, P<0.001$ ), whereas moderate improvements were found for the equivalent analysis of hot $V \mathrm{O}_{2 \max }$ changes (Hedges' $g=0.63,95 \%$ CI $0.26-1.00, P<0.001$ ), which were positively moderated by the number of days post-testing $(P=0.033, \beta=0.172)$. Meta-analysis of control vs. HA thermoneutral $V \mathrm{O}_{2 \max }$ demonstrated a small improvement in $V \mathrm{O}_{2 \max }$ in HA compared to control (Hedges' $g=0.30,95 \% \mathrm{CI} 0.06-0.54, P=0.014$ ) and this effect was larger for the equivalent hot $V \mathrm{O}_{2 \max }$ analysis where a higher (moderate-to-large) improvement in $V \mathrm{O}_{2 \max }$ was found (Hedges' $g=0.75,95 \%$ CI $0.22-1.27, P=0.005)$, with the number of HA days $(P=0.018 ; \beta=0.291)$ and the ambient temperature during HA $(P=0.003 ; \beta=0.650)$ positively moderating this effect.

Conclusion HA can enhance $V \mathrm{O}_{2 \text { max }}$ adaptation in thermoneutral or hot environments, with or without control group consideration, by at least a small and up to a moderate-large amount, with the larger improvements occurring in the heat. Ambient heat, number of induction days and post-testing days can explain some of the changes in hot $V \mathrm{O}_{2 \text { max }}$ adaptation.
\end{abstract}

Mark Waldron

mark.waldron@swansea.ac.uk

Extended author information available on the last page of the article 


\section{Key Points}

Four meta-analyses were conducted to evaluate the effects of heat acclimation or acclimatisation (HA) on maximal oxygen consumption $\left(\dot{V}_{2 \text { max }}\right)$ and factors that moderate these effects.

The collective conclusions of the meta-analyses were that HA can enhance $\dot{V} \mathrm{O}_{2 \text { max }}$ adaptation in thermoneutral (cool) or hot environments by at least a small and up to a moderate-large amount, with the descriptively largest improvements occurring in the heat.

The positive effects of $\mathrm{HA}$ on $\dot{\mathrm{V}} \mathrm{O}_{\text {max }}$ are apparent with or without the inclusion of a control group, suggesting its capacity to augment the effect of endurance training. Factors such as the level of ambient heat, the number of induction days and the post-testing days can partially moderate the change in hot $\dot{V} \mathrm{O}_{2 \max }$ adaptation.

\section{Introduction}

Maximal aerobic capacity $\left(\dot{V} \mathrm{O}_{2 \max }\right)$ is a well-established marker of cardio-respiratory fitness and related to longterm health outcomes [1-3], predicting longevity in a dose-response-dependent manner, alongside numerous other phenotypic changes [4]. In addition to the 'protective' health effects ascribed to cardiorespiratory fitness [5], $\dot{V} \mathrm{O}_{2 \max }$ is also a primary determinant of endurance performance, explaining $~ 20-60 \%$ of the variation in performances of different mode and distance, which can be realised by athletes when combined with other sub-maximal endurance performance determinants [6-8]. Despite the suggested limited trainability of $\dot{V} \mathrm{O}_{2 \max }$ [9], a number of different training approaches have been adopted to support its adaptation, such as repeated high-intensity or continuous endurance exercise, which typically confers moderate effects [10]. To augment these responses, or prepare individuals for maximal endurance exercise in hot conditions, there has been substantial interest in manipulation of environmental stressors, on the basis that exposure to a combination of exercise and hot environmental temperatures will exaggerate the effector response and subsequent stimulus for endurance adaptation [11].

Heat acclimation or acclimatisation (HA) describes processes of serial exposure to artificial or outdoor heated environments, respectively, often conducted in combination with exercise [12]. Engaging in HA enhances the capacity to thermoregulate in the heat, thus improving heat tolerance via the enhancement of various thermoregulatory mechanisms [13, 14]. Whilst it is largely agreed that HA improves exercise capacity and $\dot{V} \mathrm{O}_{2 \max }$ in the heat, its transfer to thermoneutral environments has been debated [15]. Some studies demonstrate $4-13 \%$ changes [16-21] and others report no change or a reduction following a range of HA protocols [22-28]. It was reasoned recently that insufficient post-HA adaptation periods could explain these discrepancies [21], alongside other factors, such as inter-individual differences in adaptation capacity [29]. It is possible that the HA dose (i.e. thermal load or training load) also explains the magnitude of the observed $\dot{V} \mathrm{O}_{2 \text { max }}$ adaptation [30]. Indeed, heat acclimation is most commonly conducted in combination with exercise in an 'isothermic' (fixed period of time at a fixed pre-determined core temperature) or 'iso-intensity' mode (fixed exercise intensity), which can vary in duration but typically ranges between 4 and 14 days [12]. Iso-intensity modes are preferred for acclimatisation, owing to the less controllable environment, and their time scale is often longer to account for natural variation in the environment; however, this is thought to result in adaptations that are more specific to competition, if planned correctly $[12,14]$. The selected type of heat exposure will drastically alter the subsequent stimuli for adaptation [12, 14]; however, it is not known how the selected HA modality and loading characteristics affect the adaptation of $\dot{V} \mathrm{O}_{2 \text { max }}$ in hot or thermoneutral environments. Lastly, many HA studies have been appropriately questioned [31] for the absence of control groups (i.e. participants receiving no heat exposure) in their research design. This increases the risk of biased outcome estimates ascribed to $\mathrm{HA}$ and $\dot{V} \mathrm{O}_{2 \text { max }}$ adaptation and requires further investigation.

To date, there have been meta-analyses conducted to evaluate the efficacy of HA on acclimation status and a number of physiological and performance outcomes [30, 32, 33]; however, while these articles provide detailed insights into broader questions regarding HA, their analytical focus has not been $\dot{V} \mathrm{O}_{2 \text { max }}$ adaptation. This means that a substantial number of papers have been overlooked, and the potential for disparate conclusions on this important measure of cardiorespiratory fitness is possible. Thus, there has been no comprehensive meta-analysis of all HA studies to have measured $\dot{V} \mathrm{O}_{2 \max }$ as an outcome variable. Furthermore, no study has investigated the collective moderating effect of the abovementioned factors, such as HA mode, thermal or training load and post-testing periods on $\dot{V} \mathrm{O}_{2 \text { max }}$ adaptation. Owing to the historical debate of this topic and ongoing consistency of evidence, we sought to meta-analyse all studies (with and without control groups) that have investigated the effect of $\mathrm{HA}$ on $\dot{V} \mathrm{O}_{2 \text { max }}$ adaptation in thermoneutral or hot environments. We also performed a number of meta-regressions to establish the moderating effect of selected variables on the variability in $\dot{V} \mathrm{O}_{2 \max }$ adaptation. 


\section{Methods}

\subsection{Search Strategy}

All literatures that investigated the effect of $\mathrm{HA}$ on $\dot{V} \mathrm{O}_{2 \max }$ were searched and obtained using the Preferred Reporting Items for Systematic Reviews and Meta-Analyses (PRISMA) guidelines [34], with a pre-determined search strategy. Thus, a literature search was conducted using the key search terms "heat acclimation, $\dot{V} \mathrm{O}_{2 \text { max }}$ and thermoneutral". First-order search terms used were: "heat acclimation", "acclimatisation", "heat acclimatization" and "acclimatization". Second-order search terms used were: " $V \mathrm{O}_{2 \max }$ ", "exercise performance", "aerobic capacity", "maximal oxygen uptake", "maximal aerobic power" and "temperate exercise performance". Searches were performed across four databases: PubMed, SPORTDiscus, SciDirect and Google Scholar. Other sources include social media and the reference lists of selected studies. Searches were conducted between the 6 and 8 May 2020. Following initial screening of databases, references of included studies were screened against inclusion and exclusion criteria by two authors (RF and MW) to obtain any additional studies missed from the database searches.

\subsection{Selection Criteria}

The full text of each paper was assessed separately, by two authors (RF and MW), against the below criteria to determine suitability for inclusion in the systematic review. Figure 1 illustrates the stages of selection criteria, according to

Additional records identified through other sources $(n=28)$
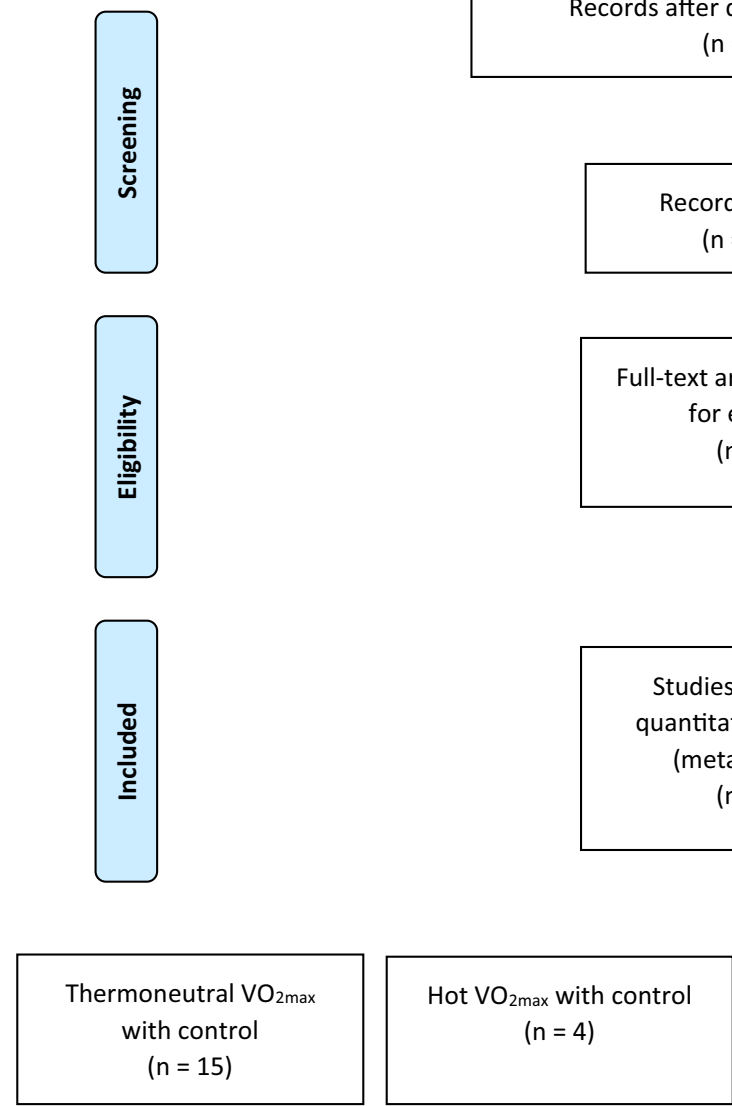

Records excluded $(n=1935)$

Full-text articles excluded for passive $\mathrm{HA}(\mathrm{n}=2)$ or non-reporting of $\mathrm{VO}_{2 \max }(\mathrm{n}$ $=2$ )

Fig. 1 Overview of the systematic review and selection process. Some articles contributed to more than one meta-analysis owing to their designs. $\mathrm{VO}_{2 \max }$ maximal oxygen consumption, $H A$ heat acclimation or acclimatisation 
the PRISMA guidelines for meta-analysis and systematic review [35]. Papers were only selected for quantitative synthesis if they satisfied the following inclusion criteria: (a) the full text was written in the English language and published in a peer-reviewed scientific journal; (b) human participants of any training background, health or gender; (c) active heat acclimation or acclimatisation of any form was utilised; (d) outcome measurements $\left(\dot{V} \mathrm{O}_{2 \max }\right)$ were performed pre- and post-HA. Abstracts and conference proceedings, $\mathrm{PhD}$ dissertations, letters, and reviews were excluded.

\subsection{Classification of Studies}

Following the exclusion of four studies, after assessment of full-text articles for eligibility, 28 peer-reviewed studies met the inclusion criteria and were categorised by the researchers into four groups, based on study design (Fig. 1), with four subsequent meta-analyses conducted, some of which necessarily included different aspects of the same study twice. The grouping of studies was as follows:

1. Thermoneutral $\dot{V} \mathrm{O}_{2 \max }$ within-participants (pre-to-post HA intervention).

2. Hot $\dot{V} \mathrm{O}_{2 \max }$ within-participants (pre-to-post HA intervention).

3. Thermoneutral $\dot{V} \mathrm{O}_{2 \max }$ measurement, with comparison between intervention and control groups.

4. Hot $\dot{V} \mathrm{O}_{2 \max }$ measurement, with comparison between intervention and control groups.

\subsection{Quality Assessment}

Quality assessment of all 28 included articles was completed independently by two authors (RF and MW) to assess for risk of bias. These were cross-checked for agreement. Seven assessment criteria were used to assess for risk of bias under the Cochrane Review criteria [36]: (1) sequence generation, (2) allocation concealment, (3) blinding of participants, (4) blinding of outcome data, (5) incomplete outcome data, (6) selective outcome reporting, and (7) other sources of bias. Each assessment criterion was judged by the review authors under three classifications, "Yes" to indicate low risk of bias, "No" to indicate high risk of bias and finally, "Unclear" to indicate level of bias is unclear or not known (Fig. 2).

\subsection{Data Extraction}

Data were extracted independently by two authors (RF and MW) and entered into a custom Excel spreadsheet for cross-checking. Collected data included: (1) characteristics of the sample (sex, health status, training status); (2) study design [isothermal or iso-intensity]; (3) HA length [days]; (4) HA session duration [min]; (5) physiological intensity; (6) mechanical intensity [W, as stated or derived] (7) HA temperature [ambient ${ }^{\circ} \mathrm{C}$ ]; (8) HA index; (9) core temperature $\left[{ }^{\circ} \mathrm{C}\right] ;(10)$ ambient thermal load [ambient temperature $\times$ session duration]; (11) post-testing period [days] and (12) $\dot{V} \mathrm{O}_{2 \max }(\mathrm{mL} / \mathrm{kg} / \mathrm{min}$ ) (Tables 1 and 2). Further descriptions of selected or derived variables are included in later sections.

For the two within-group (no control group) meta-analyses, the pre- and post-HA mean $\pm \mathrm{SD} \dot{V} \mathrm{O}_{2 \max }$ values were extracted and standardized mean differences (SMD) based thereon. For the two between-group (experimental vs. control group) meta-analyses, the post-HA or control training mean $\pm \mathrm{SD} \dot{V} \mathrm{O}_{2 \max }$ values were extracted and SMD based thereon. The analysis of post-test scores was preferred over 'change scores' owing to the inconsistency of reporting across selected studies and the resulting over-reliance on $\mathrm{SD}$ imputing. However, baseline differences in $\dot{V} \mathrm{O}_{2 \max }$ were not reported across the selected studies in the control group meta-analyses conducted herein. Furthermore, adopting meta-analysis of change scores has also been questioned for

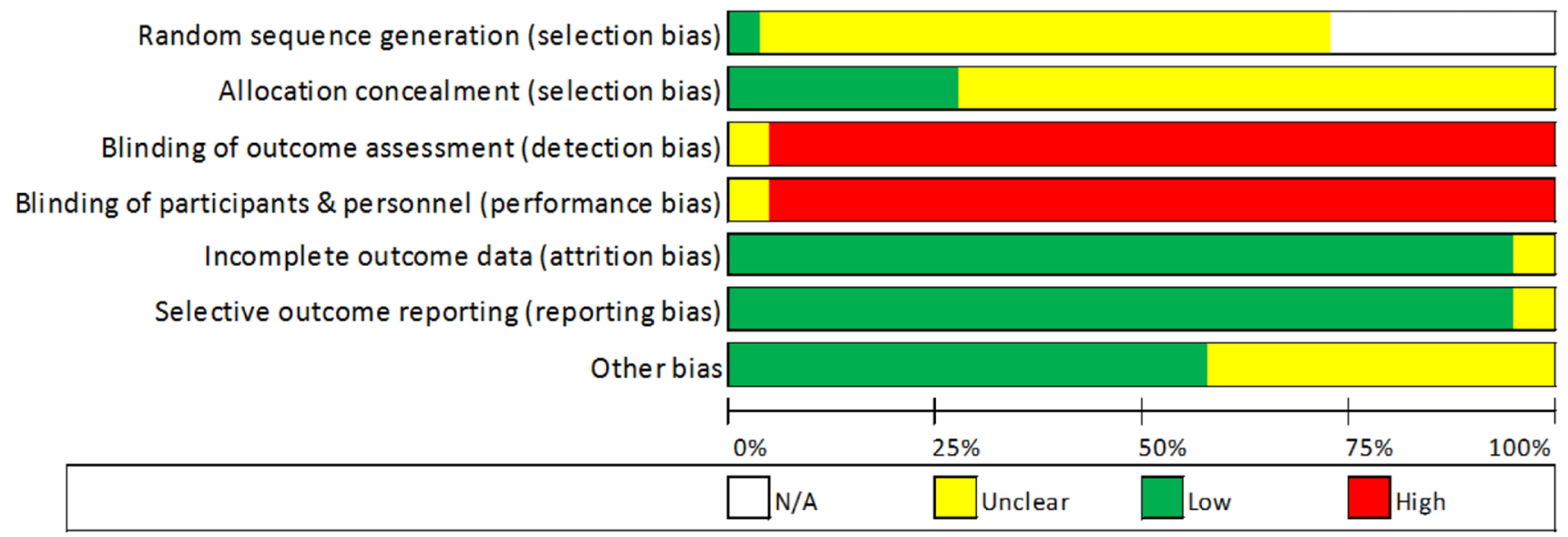

Fig. 2 Risk of bias assessment 


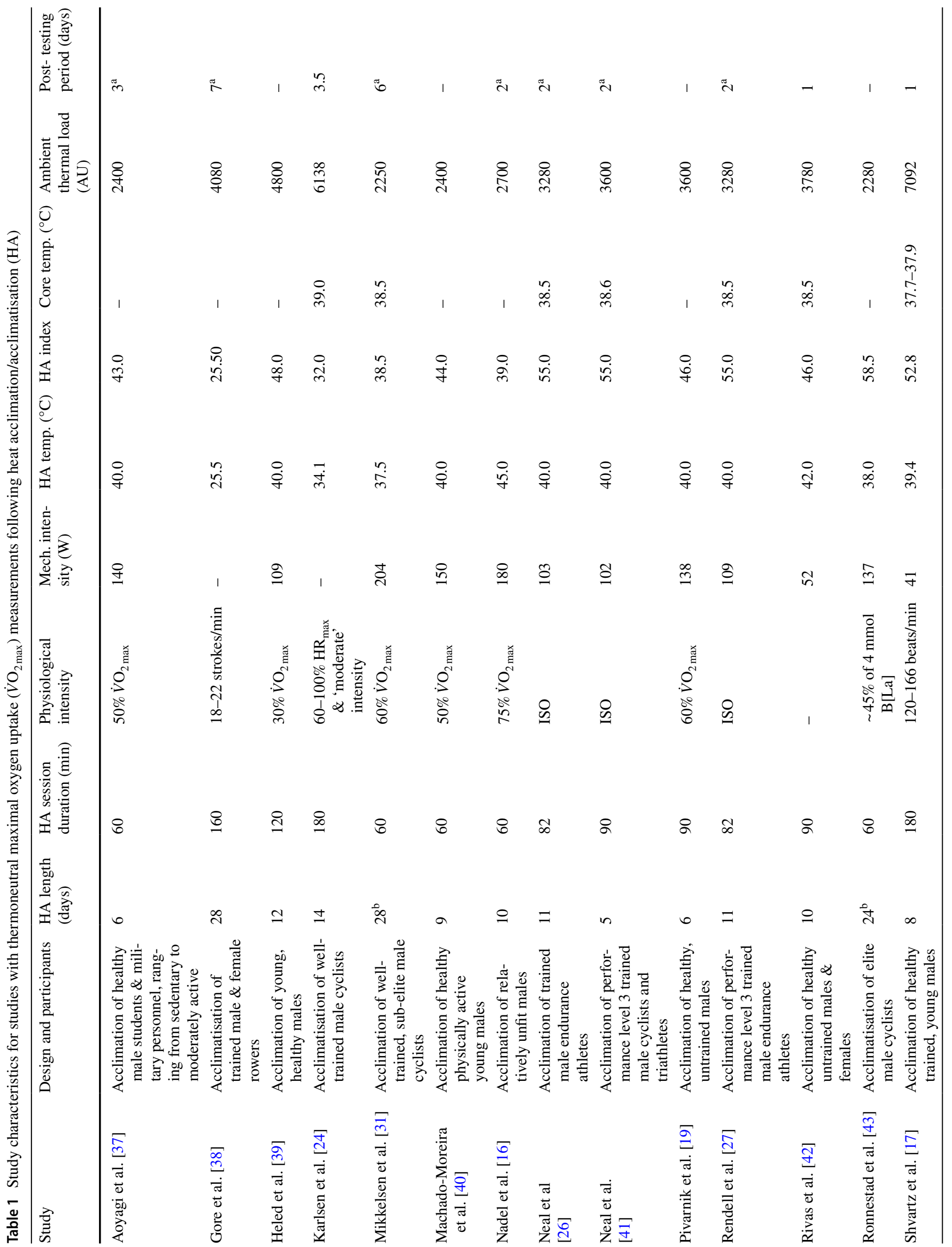




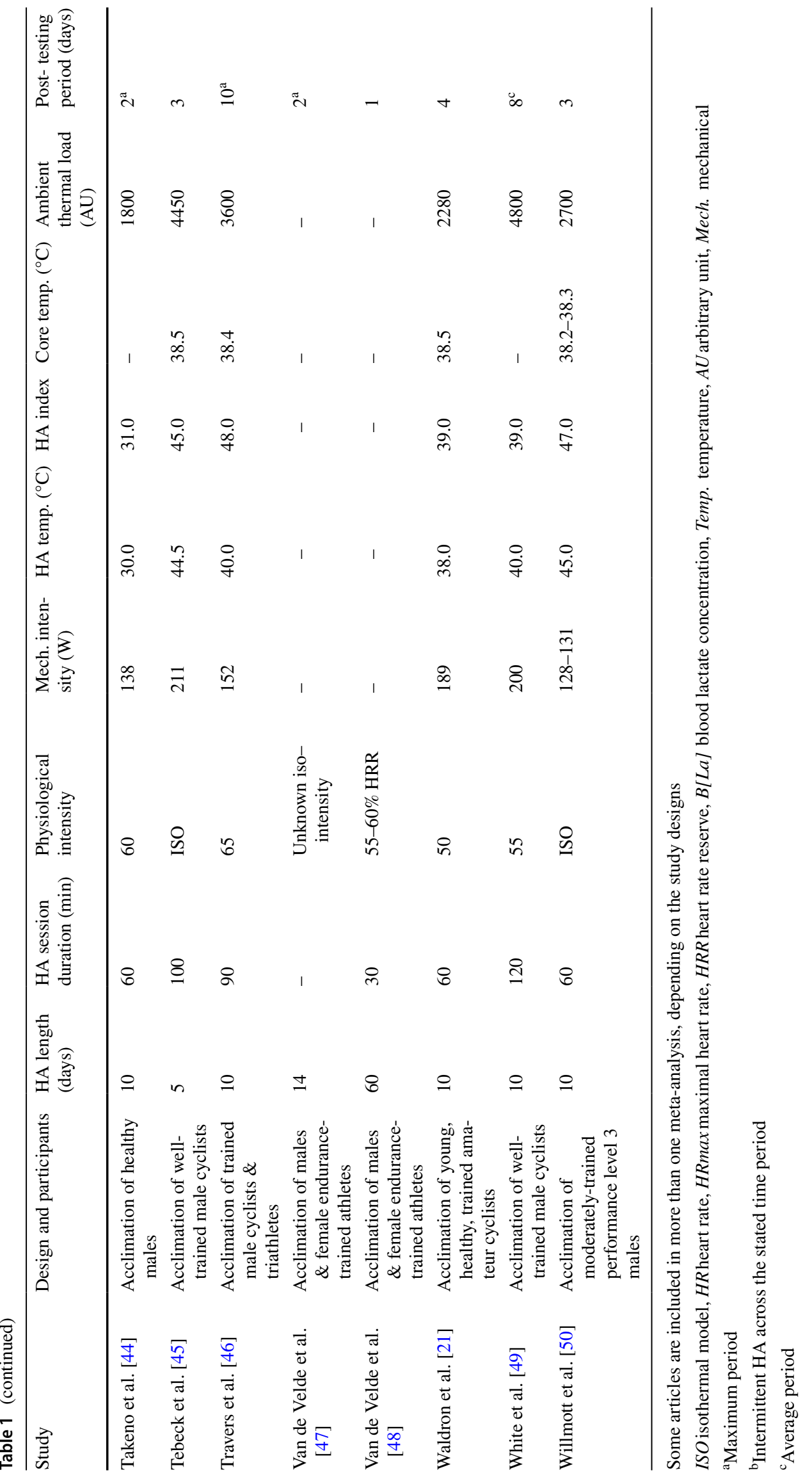




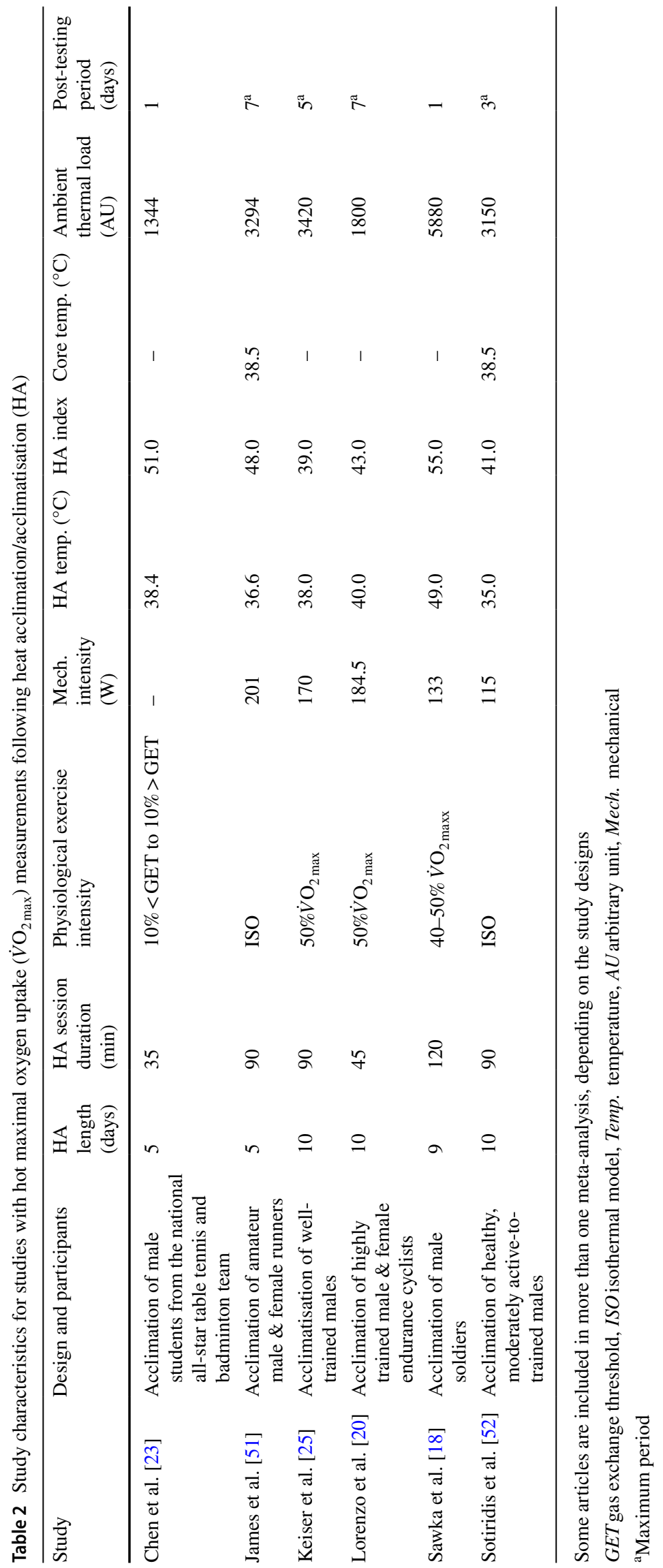


reasons relating to outcome sensitivity and exaggeration of between-subject variances $[53,54]$. Publicly available software (WebPlotDigitizer, Version 3.12) was used to extrapolate any unreported values from figures to raw mean and SD data. Both crossover and independent groups designed were considered for the control group meta-analyses. In three instances, where the experimental group was separated into independent groups within the same study, all comparisons were used in the meta-analysis [17, 38, 50].

For consistency across all of our analyses, where $\dot{V} \mathrm{O}_{2 \max }$ was reported in absolute terms (i.e. $\mathrm{mL} / \mathrm{min}$ or $\mathrm{L} / \mathrm{min}$ ), the closest reported mean body mass $(\mathrm{kg})$ to the $\dot{V} \mathrm{O}_{2 \text { max }}$ measurement was used to determine the relative $\dot{V} \mathrm{O}_{2 \text { max }}(\mathrm{mL} / \mathrm{kg} /$ $\mathrm{min}$ ) and the SD was proportionally inferred. Across all studies included, direct assessments of $\dot{V} \mathrm{O}_{2 \max }$ were performed using open-circuit spirometry in a laboratory. In one instance where insufficient SD data of pre- and post-test $\dot{V} \mathrm{O}_{2 \text { max }}$ were reported [51], the baseline (pre) SD was carried over. This was deemed to be more accurate than imputing data based on dispersions from the other studies in the meta-analysis [36] and avoided the exaggeration of the SD, which would influence the SMD result in the meta-analysis. Instances where papers had more than two experimental groups, due to additional interventions, they were matched accordingly to control or within-participant analysis. Where groups used permissive dehydration, only the data from the euhydrated participants were used in the within-participants analysis.

\subsection{Statistical Analysis}

The meta-analysis was performed in RStudio (version 4.0.0, 2020, RStudio, Inc. software, Boston, MA), using the 'metafor' package. Fixed-effects models were preferred for all analyses, owing to the homogenous nature of the samples across selected studies [55]. Descriptive data are reported as mean \pm standard deviation (SD) throughout. All effects are reported using Hedges' g standardized mean differences ( $\mathrm{SMD} \pm 95 \%$ confidence intervals; CIs) across the four different meta-analyses. Heterogeneity was assessed using the $I^{2}$ statistic.

Moderator analyses (meta-regressions) were conducted to explain additional variability in the SMD of $\dot{V} \mathrm{O}_{2 \max }$. We used weighted, random-effect meta-regressions, with maximum likelihood estimation [56]. The candidate moderators were selected based on their theorised contribution to the acclimated or endurance-adapted phenotype [11, 12]. In some cases, not all moderators could be used, owing to insufficient ( $<50 \%$ data) or inconsistent data reporting. Statistical interactions between moderators were not considered for the analyses. The moderators considered for inclusion in the meta-analyses were: acclimation/acclimatisation model (isothermal vs. iso-intensity), HA days (total days of heat exposure), HA ambient temperature $\left({ }^{\circ} \mathrm{C}\right)$, heat index [57],
HA session duration (time [min] of each HA session per visit), mean core body temperature $\left({ }^{\circ} \mathrm{C}\right)$, ambient thermal load (HA session $x$ ambient temperature), mean mechanical intensity of HA exercise (W) and the post-HA testing period (days). For isothermal protocols, the session duration was calculated based on the entire session, rather than when the target core temperature was reached. Post-testing days refer to the number of days after the HA intervention that $\dot{V} \mathrm{O}_{2 \max }$ testing took place and were recorded as reported in the manuscript as either the exact number or the maximum number of days reported. While efforts were made to describe every study consistently, some approximations were necessary for mechanical intensity. After data extraction, mean core body temperature was removed owing to consistently insufficient data. We considered it necessary to have some common indication of exercise intensity, given its potential importance for endurance adaptation [58]. For example, where mechanical power output was unreported during $\mathrm{HA}$, it was linearly extrapolated from the reported fraction of $\dot{V} \mathrm{O}_{2 \max }$ maintained during HA and corresponding peak power output values from the a priori graded exercise test [20, 25, 40, 41]. In the uncommon cases where the mechanical power output was not available during the HA or in the graded exercise test, the reported metabolic power was used to derive mechanical power using common gross efficiency values [16, 37-39, 49] for that exercise mode (inclined walking 30\% [59]; cycling 20\%; [60]). Finally, where mixed exercise designs were adopted in studies, a weighted mean value of mechanical power output was calculated, based on the time spent in different exercise modes [26, 27, 42].

Publication bias plots (i.e. funnel plots) were produced in RStudio (version 3.5.2, 2020, RStudio, Inc. software, Boston, MA), where the relationship between the effect size and the standard error of each data-set was visually inspected. Thereafter, Egger's test was conducted on all meta-analytic data-sets, with significant $(P<0.05)$ results leading to Duval and Tweedie's trim and fill correction [61]. The adjusted meta-analysis and funnel plot were then used for the current analysis. Across all analyses, the magnitudes of the effects were assessed based on the thresholds of: $0.2,0.5$ and 0.8 for small, moderate and large, respectively [62]. The effect of moderator variables was assessed based on the magnitude of the slope $(\beta)$. In all statistical analyses, a value of $P<0.05$ was considered as a significant difference. 


\section{Results}

\subsection{Within-Subject Pre-post Differences in Thermoneutral $\mathrm{VO}_{2 \text { max }}$}

The results for the meta-analysis of pre-post differences in thermoneutral $\dot{V} \mathrm{O}_{2 \text { max }}$ are reported in Fig. 3. There was a small-to-moderate improvement in $\dot{V} \mathrm{O}_{2 \text { max }}$ from pre-to-post HA (Hedges' $\mathrm{g}=0.42,95 \%$ CI $0.24-0.59, P<0.001$ ). The $I^{2}$ statistic demonstrated $51.9 \%$ heterogeneity. There was no effect $(P>0.05)$ of any moderator variables on this metaanalysis (Table 3 ).

\subsection{Within-Subject Pre-post Differences in Hot $\mathrm{VO}_{2 \max }$}

The results for the meta-analysis of pre-post differences in hot $\dot{V} \mathrm{O}_{2 \text { max }}$ are reported in Fig. 4. There was a moderate improvement in $\dot{V} \mathrm{O}_{2 \text { max }}$ from pre-to-post HA (Hedges' $g=0.63,95 \%$ CI $0.26-1.00, P<0.001)$. The $I^{2}$ statistic was $47.8 \%$. The number of days post-testing was a significant moderator of the SMD in $\dot{V} \mathrm{O}_{2 \max }(P=0.033, \beta=0.172)$, indicating that for every day after HA, a $\sim 0.17$ standardised increase in $\dot{V} \mathrm{O}_{2 \max }$ is estimated (range 1-7 days). There was no effect $(P>0.05)$ of any other moderator variables on this meta-analysis (Table 3 ).

\begin{tabular}{|c|c|c|c|c|c|c|c|c|}
\hline \multirow[b]{2}{*}{ Study } & \multicolumn{2}{|c|}{ HA Post } & \multicolumn{3}{|c|}{ HA Pre } & \multirow[b]{2}{*}{ Total } & \multirow[b]{2}{*}{ Weight } & \multirow{2}{*}{$\begin{array}{l}\text { Std. Mean Difference } \\
\text { IV, Fixed, } 95 \% \mathrm{Cl}\end{array}$} \\
\hline & Mean & SD & Total & Mean & SD & & & \\
\hline Aoyagi et al. (1994) [37] & 45.70 & 2.10 & 7 & 43.90 & 1.70 & 7 & $2.5 \%$ & $0.88[-0.23 ; 2.00]$ \\
\hline Chen et al. (2013) [23] & 53.00 & 6.50 & 7 & 53.80 & 5.20 & 7 & $2.8 \%$ & $-0.13[-1.18 ; 0.92]$ \\
\hline Gore et al. (1997) [38]1 & 57.70 & 2.70 & 4 & 57.90 & 1.50 & 4 & $1.6 \%$ & $-0.08[-1.47 ; 1.31]$ \\
\hline Gore et al. (1997) [38]2 & 50.00 & 5.20 & 5 & 52.60 & 4.80 & 5 & $1.9 \%$ & $-0.47[-1.74 ; 0.80]$ \\
\hline Heled et al. (2012)[39] & 57.10 & 2.90 & 8 & 57.00 & 3.70 & 8 & $3.2 \%$ & $0.03[-0.95 ; 1.01]$ \\
\hline Karlsen et al. (2015) [24] & 62.70 & 6.50 & 9 & 62.30 & 5.20 & 9 & $3.6 \%$ & $0.06[-0.86 ; 0.99]$ \\
\hline Keiser et al. (2015) [25] & 63.50 & 5.40 & 8 & 61.20 & 5.40 & 8 & $3.1 \%$ & $0.40[-0.59 ; 1.40]$ \\
\hline Lorenzo et al. (2010) [20] & 70.20 & 2.40 & 12 & 66.90 & 2.10 & 12 & $3.7 \%$ & $1.41[0.50 ; 2.32]$ \\
\hline Machado-Moreira et al. (2005) [40] & 53.00 & 5.00 & 6 & 54.00 & 6.00 & 6 & $2.4 \%$ & $-0.17[-1.30 ; 0.97]$ \\
\hline Mikkelsen et al. (2019) [31] & 59.80 & 1.30 & 12 & 60.00 & 1.50 & 12 & $4.8 \%$ & $-0.14[-0.94 ; 0.66]$ \\
\hline Nadel et al. (1974) [16] & 44.70 & 5.40 & 6 & 38.10 & 5.20 & 6 & $1.9 \%$ & $1.15[-0.11 ; 2.41]$ \\
\hline Neal et al. (2016) [26] & 57.80 & 9.60 & 8 & 55.20 & 7.70 & 8 & $3.1 \%$ & $0.28[-0.70 ; 1.27]$ \\
\hline Neal et al. (2016) [41] & 64.00 & 6.00 & 10 & 63.30 & 4.00 & 10 & $4.0 \%$ & $0.13[-0.75 ; 1.01]$ \\
\hline Pivarnik et al. (1987) [19] & 49.70 & 1.40 & 16 & 44.20 & 1.30 & 16 & $2.0 \%$ & $3.97[2.72 ; 5.22]$ \\
\hline Rendell et al. (2017) [27] & 56.60 & 7.00 & 8 & 56.00 & 6.50 & 8 & $3.2 \%$ & $0.08[-0.90 ; 1.06]$ \\
\hline Rivas et al. (2017) [42] & 57.10 & 5.00 & 12 & 58.00 & 6.00 & 12 & $4.8 \%$ & $-0.16[-0.96 ; 0.64]$ \\
\hline Ronnestad et al. (2020) [43] & 79.60 & 3.80 & 11 & 76.60 & 6.90 & 11 & $4.2 \%$ & $0.52[-0.33 ; 1.37]$ \\
\hline Sawka et al. (1985) [18] & 46.20 & 7.40 & 13 & 44.60 & 6.80 & 13 & $5.1 \%$ & $0.22[-0.55 ; 0.99]$ \\
\hline Schvartz et al. (1977) [17]1 & 61.70 & 2.30 & 7 & 60.10 & 2.70 & 7 & $2.6 \%$ & $0.60[-0.48 ; 1.68]$ \\
\hline Schvartz et al. (1977) [17]2 & 53.80 & 3.70 & 7 & 47.70 & 3.60 & 7 & $2.0 \%$ & $1.56[0.31 ; 2.82]$ \\
\hline Schvartz et al. (1977) [17]3 & 43.80 & 3.00 & 7 & 35.60 & 3.30 & 7 & $1.4 \%$ & $2.43[0.94 ; 3.93]$ \\
\hline Sotiridis et al. (2018) [52] & 56.70 & 6.10 & 12 & 54.70 & 5.70 & 12 & $4.7 \%$ & $0.33[-0.48 ; 1.13]$ \\
\hline Takeno et al. (2001) [44] & 54.00 & 2.10 & 5 & 50.70 & 2.40 & 5 & $1.5 \%$ & $1.32[-0.12 ; 2.77]$ \\
\hline Tebeck et al. (2019) [45] & 69.20 & 5.90 & 11 & 69.20 & 4.40 & 11 & $4.4 \%$ & $0.00[-0.84 ; 0.84]$ \\
\hline Travers et al. (2020) [46] & 54.70 & 5.90 & 8 & 52.10 & 6.50 & 8 & $3.1 \%$ & $0.40[-0.60 ; 1.39]$ \\
\hline Van de Velde et al. (2016) [47] & 54.70 & 8.30 & 12 & 50.40 & 8.80 & 12 & $4.6 \%$ & $0.49[-0.33 ; 1.30]$ \\
\hline Van de Velde et al. (2017) [48] & 57.60 & 6.30 & 7 & 52.80 & 7.30 & 7 & $2.6 \%$ & $0.66[-0.43 ; 1.75]$ \\
\hline Waldron et al. (2019) [21] & 63.60 & 5.70 & 12 & 60.90 & 6.00 & 12 & $4.6 \%$ & $0.45[-0.37 ; 1.26]$ \\
\hline White et al. (2016) [49] & 54.80 & 5.90 & 8 & 55.40 & 7.10 & 8 & $3.2 \%$ & $-0.09[-1.07 ; 0.89]$ \\
\hline Willmott et al. (2018) [50]1 & 51.20 & 6.70 & 10 & 48.70 & 5.90 & 10 & $3.9 \%$ & $0.38[-0.51 ; 1.27]$ \\
\hline Willmott et al. (2018) [50]2 & 51.70 & 5.90 & 10 & 49.70 & 6.60 & 10 & $3.9 \%$ & $0.31[-0.58 ; 1.19]$ \\
\hline $\begin{array}{l}\text { Total }(95 \% \mathrm{Cl}) \\
\text { Prediction interval } \\
\text { Heterogeneity: } \mathrm{Tau}^{2}=0.2675 ; \mathrm{Chi}^{2}\end{array}$ & & & 278 & & & 278 & $100.0 \%$ & $\begin{array}{c}0.42[0.24 ; 0.59] \\
{[-0.62 ; 1.56]}\end{array}$ \\
\hline
\end{tabular}

\section{Study}

Gore et al. (1997) [38]1

Gore et al. (1997) [38]2

Heled et al. (2012)[39]

Keiser et al. (2015) [25]

Lorenzo et al. (2010) [20]

Mikkelsen et al. (2019) [31]

Nadel et al. (1974) [16]

Pivarnik et al (1987) [19]

Rendell et al. (2017) [27]

Rivas et al (2017) [42]

Sawka et al. (1985) [18]

Schvartz et al. (1977) [17]1

Schvartz et al. (1977) [17]3

Sotiridis et al. (2018) [52]

.

Van de Velde et al. (2016) [47]

Van de Velde et al. (2017) [48]

Willmott et al. (2018) [50]1

Prediction interval

Heterogeneity: $\mathrm{Tau}^{2}=0.2675 ; \mathrm{Chi}^{2}=62.43, \mathrm{df}=30(\mathrm{P}<0.01) ; \mathrm{I}^{2}=52 \%$

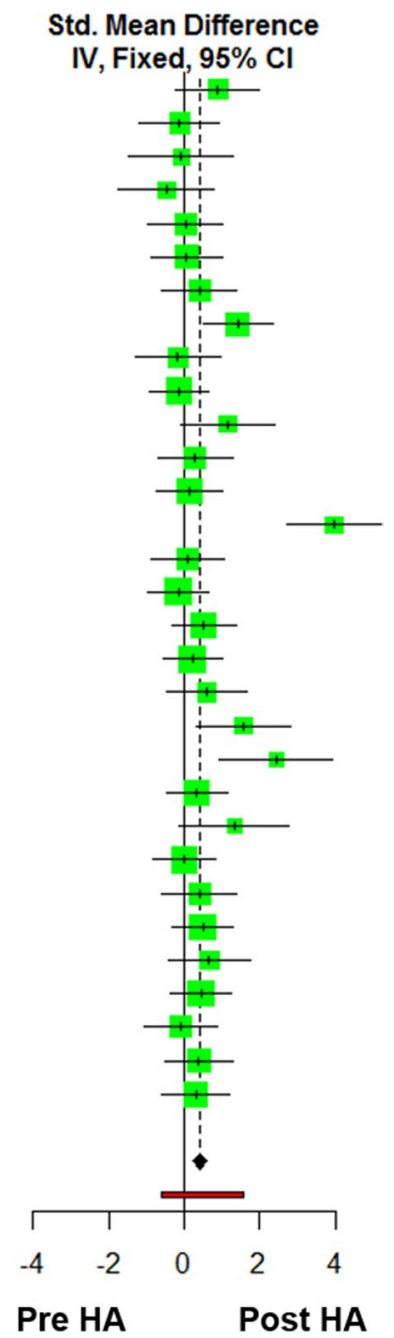

out). Numbers following the referenced article denote a separate comparison within the same study
Fig. 3 The pre-to-post, within-subject changes in thermoneutral maximal oxygen consumption ( $\dot{V} \mathrm{O}_{2 \max }$ ) following heat acclimation (HA). $S M D$ standardised mean differences, total $=$ sample size (see through- 


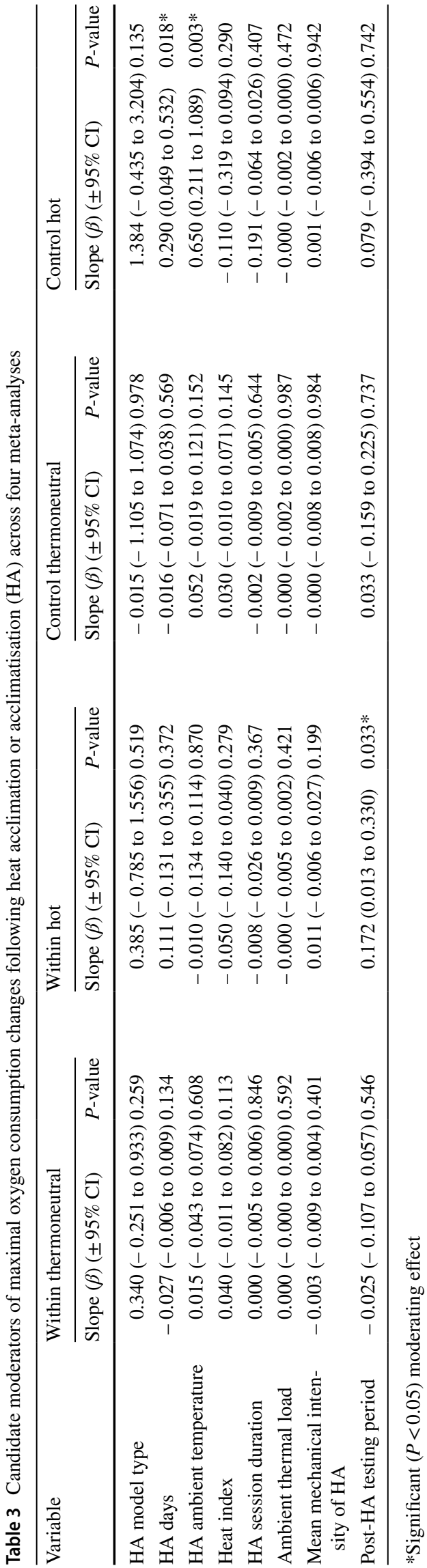

\subsection{Control vs. HA Differences in Thermoneutral $\mathrm{VO}_{2 \max }$}

The results for the meta-analysis of control vs. HA thermoneutral $\dot{V} \mathrm{O}_{2 \max }$ are reported in Fig. 5. There was a higher (small) improvement in $\dot{V} \mathrm{O}_{2 \max }$ in HA compared to control (Hedges' $g=0.30,95 \%$ CI $0.06-0.54, P=0.014)$. The $I^{2}$ statistic was $51.2 \%$. There was no effect $(P>0.05)$ of any moderator variables on this meta-analysis (Table 3 ).

\subsection{Control vs. HA Differences in $\mathrm{Hot} \mathrm{VO}_{2 \text { max }}$}

In the control vs. HA meta-analysis of hot $\dot{V} \mathrm{O}_{2 \max }$ (Fig. 6), there was a higher (moderate-to-large) improvement in $\dot{V} \mathrm{O}_{2 \max }$ in HA compared to control (Hedges' $g=0.75,95 \%$ CI $0.22-1.27, P=0.005)$. The $I^{2}$ statistic was $69.3 \%$. Both the number of HA days $(P=0.018 ; \beta=0.291)$ and the ambient temperature during HA $(P=0.003 ; \beta=0.650)$ were moderators of this effect (Table 3$)$, indicating a greater change in $\dot{V} \mathrm{O}_{2 \text { max }}$ in hotter ambient temperatures and longer acclimation periods.

\subsection{Risk of Bias}

The studies included had a generally low risk of bias, with outcome data reported thoroughly and completely for the purposes of the current meta-analyses. Given the nature of $\mathrm{HA}$, there were necessary risks of blinding and in selected studies, only experimental groups were chosen, thus voiding random sequencing (Fig. 2). Figure 7 shows that publication bias analysis (standard mean differences and standard error relationship) was generally symmetrical, with minimal outliers [see sect. 2.6 for trim and fill procedures, which were applied to panels a and c (Fig. 7)].

\section{Discussion}

We conducted four meta-analyses to evaluate the efficacy of HA on $\dot{V} \mathrm{O}_{2 \text { max }}$ adaptation in thermoneutral or hot environments, as well as establishing the moderating effect of selected variables on the magnitude of adaptation reported across studies. This has particular relevance for those intending to utilise HA to increase aerobic capacity in cool or hot environments, such as athletes or military personnel. Across all meta-analyses, there was an improvement in $\dot{\mathrm{V}} \mathrm{O}_{2 \max }$ following HA, ranging from 0.30 (small) to 0.76 (moderate-large) standardised mean changes. These significant improvements were found, irrespective of the hot or thermoneutral environment used during testing, although there were stronger effects in the hot $\dot{V} \mathrm{O}_{2 \max }$ test results. This is consistent with the general recommendation that hot training confers adaptations to performance tests in environments 


\begin{tabular}{|c|c|c|c|c|c|c|c|c|}
\hline \multirow[b]{2}{*}{ Study } & \multicolumn{3}{|c|}{ HA Post } & \multicolumn{2}{|c|}{ HA Pre } & \multirow[b]{2}{*}{ Total } & \multicolumn{2}{|r|}{ Std. Mean Difference } \\
\hline & Mean & SD & Total & Mean & SD & & Weight & IV, Fixed, 95\% Cl \\
\hline Chen et al. (2013) [23] & 53.40 & 6.70 & 7 & 52.30 & 8.20 & 7 & $12.5 \%$ & $0.14[-0.91 ; 1.19]$ \\
\hline James et al. (2018) [51] & 62.90 & 6.70 & 10 & 58.90 & 6.70 & 10 & $17.1 \%$ & $0.57[-0.33 ; 1.47]$ \\
\hline Keiser et al. (2015) [25] & 64.20 & 5.40 & 8 & 58.60 & 5.40 & 8 & $12.4 \%$ & $0.98[-0.07 ; 2.04]$ \\
\hline Lorenzo et al. (2010) [20] & 59.60 & 2.00 & 12 & 55.10 & 2.40 & 12 & $13.6 \%$ & $1.97[0.96 ; 2.97]$ \\
\hline Sawka et al. (1985) [18] & 44.10 & 6.60 & 13 & 42.30 & 6.20 & 13 & $23.1 \%$ & $0.27[-0.50 ; 1.05]$ \\
\hline Sotiridis et al. (2018) [52] & 51.40 & 5.60 & 12 & 49.80 & 5.00 & 12 & $21.3 \%$ & $0.29[-0.51 ; 1.10]$ \\
\hline $\begin{array}{l}\text { otal }(95 \% \mathrm{Cl}) \\
\text { rediction interval }\end{array}$ & & & 62 & & & 62 & $100.0 \%$ & $\begin{array}{c}0.63[0.26 ; 1.00] \\
{[-0.78 ; 2.11]}\end{array}$ \\
\hline
\end{tabular}

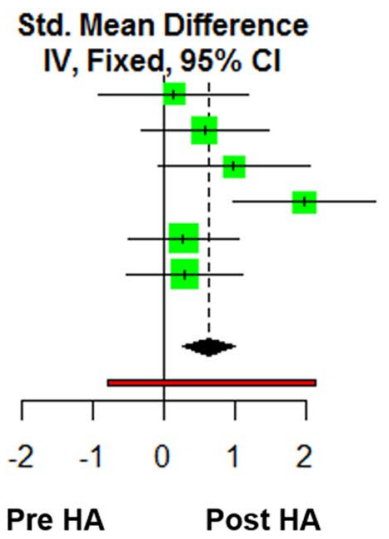

Fig. 4 The pre-to-post, within-subject changes in hot maximal oxygen consumption $\left(\dot{V} \mathrm{O}_{2 \max }\right)$ following heat acclimation (HA)

\section{Study}

Aoyagi et al. (1994) [37]

Chen et al. (2013) [23]

Gore et al. (1997) [38]1

Gore et al. (1997) [38]2

Karlsen et al. (2015) [24]

Keiser et al. (2015) [25]

Lorenzo et al. (2010) [20]

Mikkelsen et al. (2019) [31]

Rivas et al. (2017) [42]

Ronnestad et al. (2020) [43]

Schvartz et al. (1977) [17]1

Schvartz et al (1977) [17]2

Schvartz et al. (1977) [17]3

Takeno et al. (2001) [44]

Van de Velde et al. (2016) [47]

Waldron et al. (2019) [21]

Willmott et al. (2018) [50]1

Willmott et al. (2018) [50]2

Total $(95 \% \mathrm{Cl})$

Prediction interval

Heterogeneity: $\mathrm{Tau}^{2}=0.2911 ; \mathrm{Chi}^{2}=34.86, \mathrm{df}=17(\mathrm{P}<0.01) ; \mathrm{I}^{2}=51 \%$

\section{Control group}

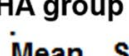

46.001 .90

53.006 .50

57.702 .70

50.005 .20

62.706 .50

63.505 .40

70.202 .40

59.801 .30

57.105 .00

79.603 .80

61.702 .30

53.803 .70

43.803 .00

54.002 .10

57.606 .30

63.605 .70

51.206 .70

51.705 .90

\section{tal Mean SD}

745.702 .10

752.404 .10

$456.90 \quad 0.90$

$5 \quad 53.101 .20$

965.305 .30

863.605 .40

1266.001 .60

1259.402 .00

1256.205 .00

1177.805 .20

$\begin{array}{lll}7 & 48.10 & 4.70\end{array}$

$\begin{array}{llll}7 & 48.10 & 4.70\end{array}$

$\begin{array}{llll}7 & 48.10 & 4.70\end{array}$

$5 \quad 57.30 \quad 3.20$

752.506 .90

1258.806 .30

1049.505 .80

$10 \quad 49.604 .10$

152
Std. Mean Difference

IV, Fixed, $95 \% \mathrm{CI}$

$0.14[-0.85 ; 1.13]$

$0.10[-0.95 ; 1.15]$

$0.40[-0.88 ; 1.69]$

$-0.69[-2.07 ; 0.69]$

-0.42 [-1.35; 0.52]

$-0.02[-1.00 ; 0.96]$

$1.89[0.78 ; 3.00]$

$0.24[-0.63 ; 1.10]$

$0.17[-0.63 ; 0.98]$

$0.38[-0.48 ; 1.25]$

$3.62[1.51 ; 5.73]$

$1.27[-0.03 ; 2.58]$

$-1.05[-2.31 ; 0.21]$

$-1.10[-2.49 ; 0.28]$

$0.72[-0.37 ; 1.82]$

$0.77[-0.06 ; 1.61]$

$0.26[-0.62 ; 1.14]$

$0.40[-0.49 ; 1.28]$

$0.30[0.06 ; 0.54]$

$[-0.89 ; 1.52]$
Std. Mean Difference

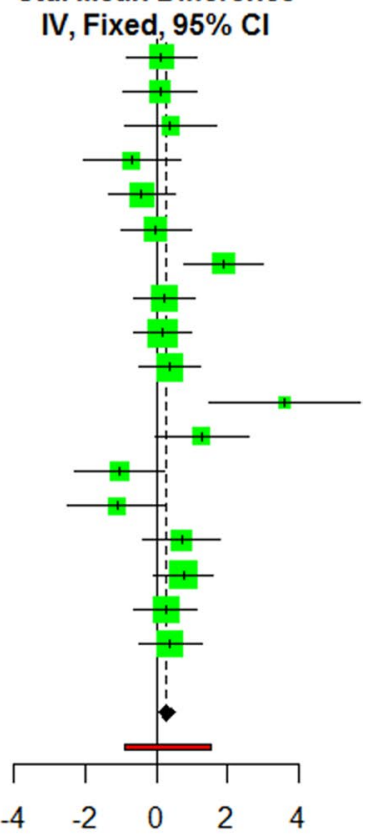

HA group

Control group

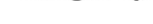

Fig. 5 Control vs. heat acclimation (HA) post-intervention comparison of thermoneutral maximal oxygen consumption $\left(\dot{V} \mathrm{O}_{2 \text { max }}\right)$. Numbers following the referenced article denote a separate comparison within the same study

\begin{tabular}{|c|c|c|c|c|c|c|c|}
\hline \multirow[b]{2}{*}{ Study } & \multicolumn{2}{|c|}{ HA group } & \multicolumn{3}{|c|}{ Control group } & \multicolumn{2}{|r|}{ Std. Mean Difference } \\
\hline & Mean & SD & Total & Mean SD & Total & Weight & IV, Fixed, $95 \% \mathrm{Cl}$ \\
\hline Chen et al. (2013) [23] & 53.40 & 6.70 & 7 & 50.605 .20 & 7 & $24.7 \%$ & $0.44[-0.63 ; 1.50]$ \\
\hline James et al. (2018) [51] & 62.90 & 6.70 & 10 & 64.305 .90 & 7 & $29.8 \%$ & $-0.21[-1.18 ; 0.76]$ \\
\hline Keiser et al. (2015) [25] & 64.20 & 5.40 & 8 & 59.502 .70 & 8 & $24.7 \%$ & $1.04[-0.02 ; 2.11]$ \\
\hline Lorenzo et al. (2010) [20] & 59.60 & 2.00 & 12 & 54.902 .30 & 8 & $20.9 \%$ & $2.12[0.96 ; 3.28]$ \\
\hline $\begin{array}{l}\text { Total }(95 \% \mathrm{Cl}) \\
\text { Prediction interval } \\
\text { Heterogeneity: } \mathrm{Tau}^{2}=0.6\end{array}$ & 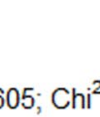 & & 37 & (R- - מ & 30 & $100.0 \%$ & $\begin{array}{c}0.75[0.22 ; 1.27] \\
{[-3.26 ; 4.90]}\end{array}$ \\
\hline
\end{tabular}

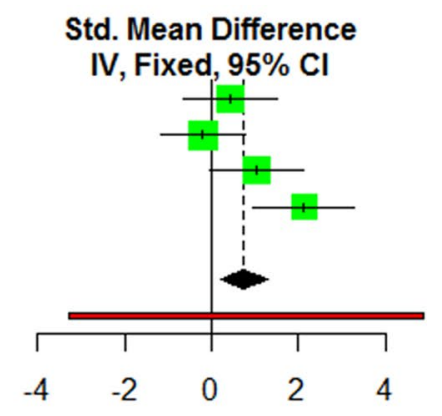

Control group

HA group

Fig. 6 Control vs. heat acclimation (HA) post-intervention comparison of hot maximal oxygen consumption $\left(\dot{V} \mathrm{O}_{2 \max }\right)$ 
Fig. 7 Risk of bias plots for measures of maximal oxygen consumption. a Heat acclimation (HA) vs. control in thermoneutral environments, $\mathbf{b}$ HA vs. control in hot environments, c pre-to-post changes in thermoneutral environments and $\mathbf{d}$ pre-to-post changes in hot environments. Hedges' $g=$ the standardised mean difference. Exp. experimental, Con control
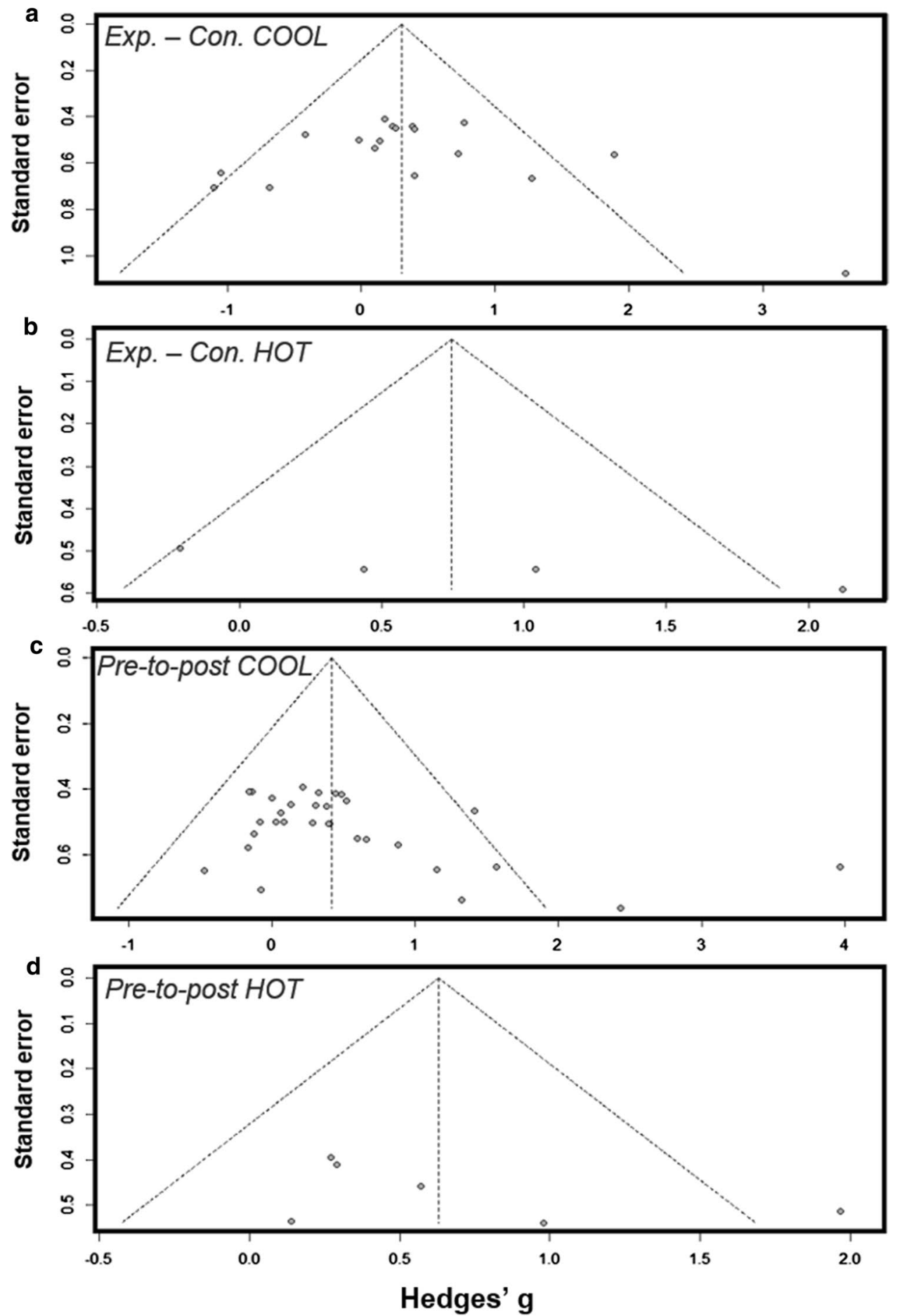

that mimic that of training [63] and were anticipated based on the principle of environmental training specificity [64, 65]. Indeed, cardiovascular adaptations to HA (see [66]) should more thoroughly prepare participants for the severe blood flow conflicts experienced during hot exercise, as compared to thermoneutral [67], and could explain the descriptively larger trend in hot $\dot{V} \mathrm{O}_{2 \max }$ changes in the heat across the meta-analyses conducted here. This is consistent with the understanding that $\dot{V} \mathrm{O}_{2 \text { max }}$ is primarily limited by central factors (i.e. cardiac output and skeletal muscle blood flow [68])_reductions of which also impair performance in the heat [67]. However, the finding of greatest importance revealed herein is that cross-adaptation does occur, with training in the heat augmenting the effect of exercise when targeting thermoneutral $\dot{V} \mathrm{O}_{2 \max }$ changes. This finding has 
implications for cardiorespiratory health in the general population [4] and contributes methods with which to enhance the classically described model of endurance performance determinants [69].

The consistent, positive effect of $\mathrm{HA}$ on $\dot{V} \mathrm{O}_{2 \max }$ across the within- and between-participant meta-analyses implies that the absence of a control group (those not receiving HA) does not appear to substantially affect the outcome. Comparison of between- (controlled) and within-participant meta-analyses analyses demonstrated that both the thermoneutral (Hedges' $g=0.42$ and 0.30 , respectively) and hot (Hedges' $g=0.63$ and 0.75 , respectively) resulted in similar changes in $\dot{V} \mathrm{O}_{2 \max }$. These results should not encourage the use of within-participant time-series designs but should arrest the debate [15] that HA is equivalent to thermoneutral training in eliciting $\dot{V} \mathrm{O}_{2 \text { max }}$ adaptations, when all studies are considered.

On the basis that the mode of HA could elicit different physiological responses, we conducted sub-analyses to determine the potential moderating effect of isothermal or isointensity programmes, which are most commonly adopted in the available literature. However, there was no effect of the adopted HA mode on $\dot{V} \mathrm{O}_{2 \text { max }}$ adaptation (Table 3). This was not anticipated, but was also supported by the finding that neither mechanical intensity nor indices of ambient thermal load during the HA programmes had a moderating effect on $\dot{V} \mathrm{O}_{2 \text { max }}$ changes (Table 3). Unfortunately, the internal core temperature responses could not be statistically assessed owing to the inconsistent or incomplete reporting of these data but descriptive observation demonstrated no trend in the relationship between $\dot{V} \mathrm{O}_{2 \text { max }}$ adaptation and core temperature during HA, in any environment (Table 3 ). Together, these results indicate that the associated increase in mechanical work rates elicited by iso-intensity models (i.e. more intense exercise) or characteristics of the isothermal models, did not influence the level of adaptation observed. These findings are at odds with the theorised necessity of higherintensity exercise for $\dot{V} \mathrm{O}_{2 \text { max }}$ adaptation during HA [21]. Indeed, the lack of difference in $\dot{V} \mathrm{O}_{2 \text { max }}$ adaptation between iso-intensity and iso-thermal designs was not anticipated, as iso-intensity models have been repeatedly shown to augment endurance performance $[21,43,70]$, which is not always the case in isothermal studies [27, 41]. It was equally surprising that the lack of moderating effect was consistent for hot $\dot{V} \mathrm{O}_{2 \text { max }}$ adaptations, since isothermal heat induction is thought to elicit the greatest thermoregulatory effects [14, 71], for the reason that core temperature can be controlled by the investigator during HA [14]. Thus, it is thought that isothermal HA is more likely to enhance the magnitude of daily thermo-effector responses and, in turn, enhances these thermoregulatory defences to a subsequent heat stimulusas is necessary for the heat acclimated phenotype [12]. Irrespective of this, the current collection of results contradict the seemingly logical inference that isothermal approaches would confer some additional benefit for maximal testing in hot conditions. This could be related to the more recently reported neutral relationship between internal thermal load (time spent $>38.5^{\circ} \mathrm{C}$ ) and changes in hallmark acclimation responses, such as core temperature or heart rate [29]. Collectively, it is likely that gross, multi-organ systemic outcome measures, such as $\dot{V} \mathrm{O}_{2 \text { max }}$, require a mixture of thermal and exercise stimuli, which varies between individuals. The recommendation, based on the current evidence, is that the choice of isothermal or iso-intensity will not affect the $\dot{V} \mathrm{O}_{2 \text { max }}$ outcome in hot or thermoneutral environments.

HA varies in the number of days over which it can be conducted, with short-term heat acclimation ( $<7$ days) facilitating partial adaptation [72-74], and long-term heat acclimation (often $\geq 7$ days) completing this process [75, 76]. This notion was partially supported in the control group meta-analysis of hot $\dot{V} \mathrm{O}_{2 \text { max }}$ adaption, where the number of HA days significantly moderated the overall effect, such that for every additional day of HA, a 0.29 (small) standardised mean increase in $\dot{V} \mathrm{O}_{2 \max }$ was observed. However, this was not the case in any of the other meta-analyses conducted herein and this particular meta-analysis was based on a total of four articles, which somewhat limits our confidence in the result. Similarly, the ambient temperature of the HA programme also explained significant variance (Table 1) in the outcome of hot $\dot{V} \mathrm{O}_{2 \text { max }}$ increases in the control group analysis, with hotter temperatures eliciting greater $\dot{V} \mathrm{O}_{2 \max }$ changes, up to a ceiling value of $40{ }^{\circ} \mathrm{C}$. Thus, notwithstanding the smaller sample of studies, longer and hotter HA programmes appear to confer the greatest effects on hot $\dot{V} \mathrm{O}_{2 \max }$ when compared to control groups. This could also relate to the specificity of the stimulus and the total heat exposure $[64,65]$ and agree with the notion that longer adaptation periods might be necessary for full hot adaptation [75, 76]. Interestingly, a recent meta-analysis reported no moderating effect of induction length (HA days) or any other parameter of HA programmes on $\dot{V} \mathrm{O}_{2 \text { max }}$ adaptation [32] but the number of studies considered for analysis was markedly less and not sub-analysed in the same manner as the current analysis. For example, $\dot{V} \mathrm{O}_{2 \max }$ assessments in hot and thermoneutral environments were amalgamated for analysis, which will produce mixed results in comparison to the current analysis, since these tasks offer distinctly different challenges.

In the meta-analysis of within-group hot $\dot{V} \mathrm{O}_{2 \text { max }}$ adaptation, we found that the post-acclimation testing period was significantly related to the outcome. Across the six studies in this analysis, we report that for every additional post-testing day immediately after the final HA intervention, a 0.17 (small) standardised change in $\dot{V} \mathrm{O}_{2 \text { max }}$ can be expected, up to a seven-day limit. In other words, testing or planned performance too close to the final day of HA is not advisable if complete hot $\dot{V} \mathrm{O}_{2 \text { max }}$ adaptation is to be realised. Extending 
this up to 7 days appears to be optimal. It should be acknowledged, however, that reporting of this was inconsistent, with many identifying the exact number of days and others stating a time period (i.e. within 7 days). Therefore, there is likely to be some variability in this moderator. Nevertheless, this is an important finding for those utilising heat acclimation to prepare for endurance exercise in hot environments and means that the suggested urgency (see [65]) to acclimate/acclimatise near to competition might be unwarranted if $\dot{V} \mathrm{O}_{2 \text { max }}$ is considered to be of greatest importance. This is inconsistent with the immediate decays reported in other physiological measures, such as core temperature and heart rate, following HA [12, 73, 77] and is likely to be related to the delayed adaptive responses (absence of immediate decay) to heat acclimation that have been demonstrated in some studies $[21,78,79]$. This phenomenon can be likened to classical dose-response theories of Seyle [80] and explained directly by the severity of the imposed internal thermal load and necessary recovery that subsequently ensues to permit phenotypic adaptation [81]. Given that this was observed in the within-participant hot $\dot{V} \mathrm{O}_{2 \text { max }}$ analysis, rather than the thermoneutral equivalents, it is possible that the specificity of the hot environment during post-testing underpins this theory. However, experimental work has recently demonstrated a similar pattern of adaptation following heat acclimation when testing in thermoneutral environments [21]. Therefore, further work is needed to understand this phenomenon and its physiological determinants.

As we anticipated, there were numerous inconsistencies between studies, which limit some of the conclusions of the current meta-analyses and should be considered when using these results to inform HA programme design. For example, core body temperature in response to HA sessions was often reported as either a mean or a final temperature reached. Whilst there is typically a relationship between these variables, it would be helpful for readers if more complete reporting of the mean, standard deviation and final core body temperatures is provided. In addition, the measurement of core body temperature (rectal, oesophageal, tympanic, ingestible pill) often varies between studies and could alter the magnitude of the response. Whilst we used SMD to control for differences in measurement type in the current meta-analyses, readers should be aware of this when evaluating the raw data we presented herein from previous studies. Finally, the number of days between HA completion and post-testing of $\dot{V} \mathrm{O}_{2 \text { max }}$ should be reported more consistently among studies, perhaps through submission of raw data to support summary findings, since this appears to affect the $\dot{V} \mathrm{O}_{2 \text { max }}$ measurement. More exact reporting of this would help to understand the consistency of this conclusion and improve the design of HA programmes, if $\dot{V} \mathrm{O}_{2 \text { max }}$ improvement is assumed to be a desirable outcome.

\section{Conclusion}

The collective conclusions drawn from the current metaanalyses are that HA can enhance $\dot{V} \mathrm{O}_{2 \text { max }}$ adaptation in thermoneutral or hot environments by at least a small and up to a moderate-large amount, with the descriptively larger improvements occurring in the heat. The positive effects of $\mathrm{HA}$ on $\dot{V} \mathrm{O}_{2 \text { max }}$ were maintained with or without the inclusion of a control group, suggesting its capacity to augment the effect of endurance training. The type of programme adopted (isothermal or iso-intensity) did not appear to affect the training adaptation but the ambient heat and number of induction days do explain the change in hot $\dot{V} \mathrm{O}_{2 \text { max }}$ adaptation, which could support the necessity of higher thermal volumes (exposures) and similarity of the training to the testing environment to maximise adaptation. The number of post-testing days also appears to play a role in hot $\dot{V} \mathrm{O}_{2 \max }$ adaptation and further work is required to explain the underlying physiology of this delayed response.

\section{Declarations}

Authorship contributions MW and RF performed the searches, screening of manuscripts, study quality scoring. MW performed the data analysis. All authors (MW, RF, JT, OJ, SH and LK) assisted with data interpretation and drafting of the manuscript, as well reading and approving the final version of the manuscript.

Funding No funding was provided to support this manuscript.

Conflict of interest/Competing interests Mark Waldron, Rebecca Fowler, Shane Heffernan, Jamie Tallent, Liam Kilduff and Owen Jeffries have no conflicts of interest directly relevant to the content of this article.

Ethics approval Not applicable.

Consent to participate Not applicable.

Consent for publication Not applicable.

Availability of data and material Available on request.

Code availability Not applicable.

Open Access This article is licensed under a Creative Commons Attribution 4.0 International License, which permits use, sharing, adaptation, distribution and reproduction in any medium or format, as long as you give appropriate credit to the original author(s) and the source, provide a link to the Creative Commons licence, and indicate if changes were made. The images or other third party material in this article are included in the article's Creative Commons licence, unless indicated otherwise in a credit line to the material. If material is not included in the article's Creative Commons licence and your intended use is not permitted by statutory regulation or exceeds the permitted use, you will need to obtain permission directly from the copyright holder. To view a copy of this licence, visit http://creativecommons.org/licenses/by/4.0/. 


\section{References}

1. Keteyian SJ, Brawner CA, Savage PD, Ehrman JK, Schairer J, Divine G, et al. Peak aerobic capacity predicts prognosis in patients with coronary heart disease. Am Heart J. 2008;156:292-300.

2. Perry CGR, Heigenhauser GJF, Bonen A, Spriet LL. Highintensity aerobic interval training increases fat and carbohydrate metabolic capacities in human skeletal muscle. Appl Physiol Nutr Metab. 2008;33:1112-23.

3. Ross R, Blair SN, Arena R, Church TS, Després J, Franklin BA, et al. Importance of assessing cardio respiratory fitness in clinical practice: a case for fitness as a clinical vital sign: a scientific statement from the American heart association. Circulation. 2016;134:e653-99.

4. Clausen JSR, Marott JL, Holtermann A, Gyntelberg F, Jensen MT. Midlife cardiorespiratory fitness and the long-term risk of mortality: 46 years of follow-up. J Am Coll Cardiol. 2018;72:987-95.

5. Bacon AP, Carter RE, Ogle EA, Joyner MJ. $\mathrm{VO}_{2 \max }$ trainability and high intensity interval training in humans: a meta-analysis. PLoS One. 2013. https://doi.org/10.1371/journal.pone.0073182.

6. Coyle EF, Coggan AR, Hopper MK, Walters TJ. Determinants of endurance in well-trained cyclists. J Appl Physiol. 1988;64:2622-30.

7. Schabort EJ, Killian DC, Gibson SCA, Hawley JA, Noakes TD. Prediction of triathlon race time from laboratory testing in national triathletes. Med Sci Sports Exerc. 2000;32:844-9.

8. Jacobs RA, Rasmussen P, Siebenmann C, Díaz V, Gassmann M, Pesta D, et al. Determinants of time trial performance and maximal incremental exercise in highly trained endurance athletes. J Appl Physiol. 2011;111:1422-30.

9. Bouchard C, Sarzynski MA, Rice TK, Kraus WE, Church TS, Sung YJ, et al. Genomic predictors on the $\mathrm{O}_{2}$ uptake response to standardized exercise training programs. J Appl Physiol. 2011;110:1160-70.

10. Milanović Z, Sporiš G, Weston M. Effectiveness of high-intensity interval training (HIT) and continuous endurance training for VO2max improvements: a systematic review and meta-analysis of controlled trials. Sports Med. 2015;45:1469-81.

11. Corbett J, Neal RA, Lunt HC, Tipton MJ. Adaptation to heat and exercise performance under cooler conditions: a new hot topic. Sports Med. 2014;44:1323-31.

12. Daanen HAM, Racinais S, Périard J. Heat acclimation decay and re-acclimation: a systematic review and meta-analysis. Sports Med. 2018;48:409-30.

13. Sawka MN, Leon LR, Montain SJ, Sonna LA. Integrated physiological mechanisms of exercise performance, adaptation and maladaptation to heat stress. Compr Physiol. 2011;1:1883-928.

14. Taylor N, Cotter J. Heat adaptation: guidelines for the optimisation of human performance. Int Sports Med J. 2006;7:33-5.

15. Nybo L, Lundby C. CrossTalk opposing view: Heat acclimatization does not improve exercise performance in a cool condition. $\mathrm{J}$ Physiol. 2016;594:245-7.

16. Nadel ER, Pandolf KB, Roberts MF, Stolwijk JA. Mechanisms of thermal acclination to exercise and heat. J Appl Physiol. 1974;37:515-20.

17. Shvartz E, Shapiro Y, Magazanik A, Meroz A, Birnfeld H, Mechtinger A, et al. Heat acclimation, physical fitness, and responses to exercise in temperate and hot environments. J Appl Physiol Respir Environ Exerc Physiol. 1977;43:678-83.

18. Sawka MN, Young AJ, Cadarette BS, Levine L, Pandolf KB. Influence of heat stress and acclimation on maximal aerobic power. Eur J Appl Physiol Occup Physiol. 1985;53:294-8.
19. Pivarnik JM, Goetting MP, Senay LC. Effect of endurance training and heat acclimation on aerobic capacity, blood volume and plasma testosterone. J Appl Sports Sci Res. 1987;1:33-5.

20. Lorenzo S, Halliwill JR, Sawka MN, Minson CT. Heat acclimation improves exercise performance. J Appl Physiol. 2010;109:1736-43.

21. Waldron M, Jeffries O, Tallent J, Patterson S, Nevola V. The time course of adaptations in thermoneutral maximal oxygen consumption following heat acclimation. Eur J Appl Physiol. 2019;119:2391-9.

22. Houmard JA, Costill DL, Davis JA, Mitchell JB, Pascoe DD, Robergs RA. The influence of exercise intensity on heat acclimation in trained subjects. Med Sci Sports Exerc. 1990;22:615-20.

23. Chen TI, Tsai PH, Lin JH, Lee NY, Liang MT. Effects of shortterm heat acclimation on endurance time and skin blood flow in trained athletes. Open Access J Sports Med. 2013;18:161-70.

24. Karlsen A, Racinais S, Jensen VM, Norgaard SJ, Bonne TC, Nybo L. Heat acclimatization does not improve $\mathrm{VO}_{2 \max }$ or cycling performance in a cool climate in trained cyclists. Scand J Med Sci Sports. 2015;25:269-76.

25. Keiser S, Flück D, Hüppin F, Stravs A, Hilty MP, Lundby C. HA increases exercise capacity in hot but not in temperate conditions: a mechanistic counter-balanced cross-over study. Am J Physiol Heart Circ Physiol. 2015;309:750-61.

26. Neal RA, Massey HC, Tipton MJ, Young JS, Corbett J. Effect of permissive dehydration on induction and decay of heat acclimation, and temperate exercise performance. Front Physiol. 2016. https://doi.org/10.3389/fphys.2016.00564.

27. Rendell RA, Prout J, Costello JT, Massey HC, Tipton MJ, Young JS, Corbett J. Effects of 10 days of separate heat and hypoxic exposure on heat acclimation and temperate exercise performance. Am J Physiol Regul Integr Comp Physiol. 2017;313:191-201.

28. Sotiridis A, Miliotis P, Ciuha U, Koskolou M, Mekjavic IB. No ergogenic effects of a 10 day combined heat and hypoxic acclimation on aerobic performance in normoxic thermoneitral or hot conditions. Eur J Appl Physiol. 2019. https://doi.org/10.1007/ s00421-019-04215-5.

29. Corbett J, Rendell RA, Massey HC, Costello JT, Tipton MJ. Interindividual variation in the adaptive response to heat acclimation. J Therm Biol. 2018;74:29-36.

30. Tyler CJ, Reeve T, Hodges GI, Cheung SS. The effects of heat adaptation on physiology, perception and exercise performance in the heat: a meta-analysis. Sports Med. 2016;46:1699-724.

31. Mikklesen CJ, Junge N, Piil JF, Morris NB, Oberholzer L, Siebenmann $\mathrm{C}$, et al. Prolonged heat acclimation and aerobic performance in endurance trained athletes. Front Physiol. 2019. https:// doi.org/10.3389/fphys.2019.01372.

32. Benjamin CL, Sekiguchi Y, Fry LA, Casa DJ. Performance changes following heat acclimation and the factors that influence these changes: meta-analysis and meta-regression. Front Physiol. 2019. https://doi.org/10.3389/fphys.2019.01448.

33. Rahimi GRM, Albanaqi AL, Van der Touw T, Smart NA. Physiological responses to heat acclimation: A systematic review and meta-analysis of randomized controlled trials. J Sport Sci Med. 2019;18:316-26.

34. Moher D, Shamseer L, Clarke M, Ghersi D, Liberati A, Petticrew M, PRISMA-P group, et al. Preferred reporting items for systematic review and meta-analysis protocols (PRISMA-P) 2015 statement. Syst Rev. 2015;4:1. https://doi.org/10.1186/2046-4053-4-1.

35. Liberati A, Altman DG, Tetzlaff J, Multrow C, Gøtzsche PC, Ioanindis JPA, et al. The PRISMA statement for reporting systematic reviews and meta-analyses of studies that evaluate health care interventions: explanation and elaboration. J Clin Epidemiol. 2009;62:1-34.

36. Higgins JPT, Savović J, Page MJ, Elbers RG, Sterne JAC. Assessing Risk of bias in randomized trial. In: Higgins JPT, Thomas 
J, Chandler J, Cumpston M, Li T, Page MJ, Welch VA, editors. Cochrane handbook for systematic reviews of interventions. Wiley; 2019. p. 207-27.

37. Aoyagi Y, McLellan TM, Shephard RJ. Effects of training and acclimation on heat tolerance in exercising men wearing protective clothing. Eur J Appl Physiol. 1994;68:234-45.

38. Gore CJ, Hahn AG, Burge CM, Telford RD. $\mathrm{VO}_{2 \max }$ and haemoglobin mass of trained athletes during high intensity training. Int J Sports Med. 1997;18:477-82.

39. Heled Y, Peled A, Yanovich R, Shargal E, Pilz-Burstein R, Epstein $\mathrm{Y}$, et al. Heat acclimation and performance in hypoxic conditions. Aviat Space Environ Med. 2012;83:649-53.

40. Machado-Moreira CA, Magalhães FC, Vimieiro-Gomes AC, Lima NRV, Oswaldo L, Rodrigues C. Effects of heat acclimation on sweating during graded exercise until exhaustion. J Therm Biol. 2005;30:437-42.

41. Neal RA, Corbett J, Massey HC, Tipton MJ. Effect of short-term heat acclimation with permissive dehydration on thermoregulation and temperate exercise performance. Scand J Med Sci Sports. 2016;26:875-84.

42. Rivas E, Rao M, Castleberry T, Ben-Ezra V. The change in metabolic heat production is a primary mediator of heat acclimation in adults. J Therm Biol. 2017;70:69-79.

43. Rønnestad BR, Hamarsland H, Hansen J, Holen E, Montero E, Whist JE, et al. Five weeks of HA increases haemoglobin mass in elite cyclists. Exp Physiol. 2020. https://doi.org/10.1113/EP088 544.

44. Takeno Y, Kamijo YI, Nose H. Thermoregulatory and aerobic changes after endurance training in a hypobaric hypoxic and warm environment. J Appl Physiol. 2001;91:1520-8.

45. Tebeck ST, Buckley JD, Bellenger CR, Stanley J. Differing physiological adaptations induced by dry and humid short-term heat acclimation. Int J Sports Physiol Perform. 2019;15:133-40.

46. Traver G, Nichols D, Riding N, González-Alonso J, Périard JD. Heat acclimation with controlled heart rate: Influence of hydration status. Med Sci Sports Exerc. 2020;52:1815-24.

47. Van de Velde SS, Byrd BR, Fargo JS, Buchanan CA, Dalleck LC. The performance benefits of training with a sauna suit: A randomized, controlled trial. Int J Res Exerc Physiol. 2017;13:1-11.

48. Van de Velde SS, St Pierre IA, Byrd BR, Fargo JS, Loring LB, Dalleck LC. Effects of exercise training with a sauna suit on cardiovascular health: a proof of concept study. Int J Res Exerc Physiol. 2016;11:1-10.

49. White AC, Salgado RM, Astorino TA, Loeppky JA, Schneider SN, McCormick JJ, et al. The effect on 10 days of heat acclimation on exercise performance in acute hypobaric hypoxia (4350m). Temperature. 2015;3:176-85.

50. Willmott AGB, Hayes M, James CA, Dekerle J, Gibson OR, Maxwell NS. Once- and twice-daily heat acclimation confer similar heat adaptations, inflammatory responses and exercise tolerance improvements. Physiol Rep. 2018. https://doi.org/10.14814/phy2. 13936.

51. James CA, Richardson AJ, Watt PW, Willmott AG, Gibson OR, Maxwell NS. Short term heat acclimation improves the determinants of endurance performance and 5,000 m running performance in the heat. Appl Physiol Nutr Metab. 2018;42:285-94.

52. Sotiridis A, Debevec T, Ciuha U, Eiken O, Mekjavic IB. Heat acclimation does not affect maximal aerobic power in thermoneutral normoxic or hypoxic conditions. Exp Physiol. 2018. https:// doi.org/10.1113/EP087268.

53. Fu R, Holmer HK. Change score or follow-up score? Choice of mean difference estimates could impact meta-analysis conclusions. J Clin Epidemiol. 2016;76:108-17.

54. Cuijpers P, Weitz E, Cristea IA, Twisk J. Pre-post effect sizes should be avoided in meta-analyses. Epidemiol Psych Sci. 2017;26:364-8.
55. Borenstein M, Hedges LV, Higgins JPT, Rothstein HR. Introduction to meta-analysis. Wiley; 2009.

56. Hedges LV, Olkin I. Statistical method for meta-analysis. Academic Press; 2014.

57. Steadman RG. The assessment of sultriness. Part I: a temperaturehumidity index based on human physiology and clothing science. J Appl Meteorol. 1978;18:861-73.

58. Laursen PB. Training for intense exercise performance: highintensity or high-volume training? Scand J Med Sci Sports. 2010. https://doi.org/10.1111/j.1600-0838.2010.01184.x.

59. Minetti AE, Ardigò LP. The transmission efficiency of backward walking at different gradients. Eur J Physiol. 2001;442:542-6.

60. Ettema G, Lorås HW. Efficiency in cycling: a review. Eur J Appl Physiol. 2009;106:1-14.

61. Duval S. The trim and fill method. In: Rothstein HR, Sutton AJ, Borenstein M, editors. Publication bias in meta-analysis: prevention, assessment and adjustments. Wiley; 2005. p. 127-44.

62. Rosenthal R, Rosnow RL. Essentials of behavioural research: method and data analysis. McGraw-Hill; 1984.

63. Racinais S, Alonso JM, Coutts AJ, Flouris AD, Girard O, González-Alonso J, et al. Consensus recommendations on training and competing in the heat. Br J Sports Med. 2015;49:1164-73.

64. Périard JD, Racinais S, Sawka MN. Adaptations and mechanisms of human heat acclimation: applications for competitive athletes and sports. Scand J Med Sci Sports. 2015;52:20-38.

65. Pryor JL, Johnson EC, Roberts WO, Pryor RR. Application of evidence-based recommendation for heat acclimation: Individual and team sport perspectives. Temperature. 2019;6:37-49.

66. Périard JD, Traver GJS, Racinais S, Sawka MN. Cardiovascular adaptations supporting human exercise-heat acclimation. Auton Neurosci. 2016;196:52-62.

67. González-Alonso J, Crandall CG, Johnson JM. The cardiovascular challenge of exercising in the heat. J Physiol. 2008;568:45-53.

68. Bassett DR, Howley ET. Limiting factors for maximum oxygen uptake and determinants of endurance performance. Med Sci Sports Exerc. 2000;32:70-84.

69. Joyner MJ, Coyle EF. Endurance exercise performance: the physiology of champions. J Physiol. 2008;568:35-44.

70. Lorenzo S, Minson CT. Heat acclimation improves cutaneous vascular function and sweating in trained cyclists. J Appl Physiol. 2010;109:1736-43.

71. Fox RH, Goldsmith R, Kidd DJ, Lewis HE. Acclimatization to heat in man by controlled elevation of body temperature. J Physiol. 1963;166:530-47.

72. Chalmers S, Esterman A, Eston R, Bowering KJ, Norton K. Shortterm heat acclimation training improves physical performance: A systematic review, and exploration of physiological adaptations and application for team sports. Sports Med. 2014;44:971-88.

73. Garrett AT, Rehrer NJ, Patterson MJ. Induction and decay of short-term heat acclimation in moderately and highly trained athletes. Sports Med. 2011;41:757-71.

74. Pandolf KB. Effects of physical training and cardiorespiratory physical fitness on exercise-heat tolerance: recent observations. Med Sci Sports. 1979;11:60-5.

75. Gibson OR, Mee JA, Tuttle JA, Taylor L, Watt PW, Maxwell NS. Isothermic and fixed intensity heat acclimation methods induce similar heat adaptation following shot and long-term timescales. J Therm Biol. 2015;49:55-65.

76. Kirby NV, Lucas SJE, Lucas RAI. Nine-, but not four-days heat acclimation improves self-paced endurance performance in females. Front Physiol. 2019. https://doi.org/10.3389/fphys.2019. 00539.

77. Garrett AT, Goosens NG, Rehrer NJ, Patterson MJ, Cotter JD. Induction and decay of short-term heat acclimation. Eur J Appl Physiol. 2009;107:659-70. 
78. Daanen HAM, Jonkman AG, Layden JD, Linnane DM, Weller AS. Optimising the acquisition and retention of heat acclimation. Int J Sports Med. 2011;32:822-8.

79. Weller AS, Linnane DM, Jonkman AG, Daanan HA. Quantification of the decay and re-induction of heat acclimation in dry-heat following 12 and 26 days without exposure to heat stress. Eur J Appl Physiol. 2007;102:57-66.
80. Selye H. Stress and general adaptation syndrome. Br Med J. 1950;1:1383-92.

81. Pandolf KB, Burse RL, Goldman RF. Role of physical fitness in heat acclimatisation, decay and re-induction. Ergonomics. 1977;20:399-408.

\title{
Authors and Affiliations
}

\author{
Mark Waldron $^{1,2,3}$ (D) $\cdot$ Rebecca Fowler $^{4} \cdot$ Shane Heffernan $^{1} \cdot$ Jamie Tallent $^{4} \cdot$ Liam Kilduff $^{1,2} \cdot$ Owen Jeffries $^{5}$ \\ $1 \quad$ A-STEM Centre, College of Engineering, Swansea \\ University, Swansea, UK \\ 2 Welsh Institute of Performance Science, Swansea University, \\ Swansea, UK \\ 4 Sport, Health and Applied Sciences, St Mary's University, \\ London, UK \\ 5 School of Biomedical, Nutritional and Sport Sciences, \\ Newcastle University, Newcastle Upon Tyne, UK
}

3 School of Science and Technology, University of New England, Armidale, NSW, Australia 